Шумилина В.Е., канд. экон. наук, доцент кафедры «Экономическая безопасность, учет и право» ФГБОУ ВО ДГТУ, г. Ростов-на-Дону, Россия;

Калинина А.А., студент 4 курса кафедры «Экономическая безопасность, учет и право» ФГБОУ ВО ДГТУ, г. Ростов-на-Дону, Россия Котенко Н.С.студент 4 курса кафедры «Экономическая безопасность, учет и право» ФГБОУ ВО ДГТУ, г. Ростов-на-Дону, Россия

\title{
ФИНАНСОВОЕ ПЛАНИРОВАНИЕ НА ПРЕДПРИЯТИИ
}

Аннотация.Статья посвящена исследовательскому анализу типового финансового планирования на предприятии. Проводится поиск закономерностей и тенденций в финансовом планировании. Описаны этапы создания финансового плана. Показаны различные методы финансового планирования и раскрыта важность управляющего персонала в принятии управленческих решений.Раскрыты текущие закономерности в финансовом менеджменте. Структурирован процесс финансового менеджмента. В заключение были сделаны выводы, что системность финансового менеджмента зависит от крупности предприятия. Главная цель предприятия получение прибыли, и добиться этого возможно при помощи финансового менеджмента.

Ключевые слова: учет, управленческий учет, бюджет, управление, финансовый менеджмент, финансовый план, структуризация, бизнеспроцессы, оптимизация управления, предельные значения, прибыльность, целевые показатели.

Shumilina V.E., Cand. econom. Sciences, Associate Professor of the Department of «Economic security, accounting and law» DSTU, Rostov-on-Don, Russia; 
Kalinina A.A., 4th year student of the Department of "Economic security, accounting and law " DSTU, Rostov-on-Don, Russia

Kotenko N.S., 4th year student of the Department of "Economic security, accounting and law " DSTU, Rostov-on-Don, Russia

\section{FINANCIAL PLANNING AT THE ENTERPRISE}

Annotation. The article is devoted to the research analysis of typical financial planning at the enterprise. The search for patterns and trends in financial planning is carried out. The stages of creating a financial plan are described. Various methods of financial planning are shown and the importance of managing personnel in making managerial decisions is revealed. The current patterns in financial management are revealed. The financial management process is structured. In conclusion, it was concluded that the consistency of financial management depends on the size of the enterprise. The main goal of the company is to make a profit and it is possible to achieve this with the help of financial management

Keywords: accounting, management accounting, budget, management, financial management, financial plan, structuring, business processes, management optimization, limits, profitability, targets.

Современные предприятия невозможно представить без внутрифирменного финансового планирования.Такой вид планирования основывается на определенном организационном обеспечении. Это означает, что для независимой компании отдельный управляющий определяет субъекты планирования и процесс взаимодействия между ними и с другими подсистемами контроля. Данная организационная система характерна для любого предприятия, осуществляющего экономическую деятельность, так 
как финансовое планирование - это основа развития предприятия. Состав субъектов планирования зависит от масштаба предприятия, его экономической функции, и от нужд управляющего персонала. На экономически состоявшихся предприятиях таким планированием занимается специализированный персонал, подчиненный руководству. Однако, если предприятие недостаточно крупное, таким видом менеджмента занимаются руководитель и главный бухгалтер. Необходимо также отметить, что на структуру системы финансового планирования влияет степень децентрализации плановых процессов (существуют процессы, которые могут быть децентрализованные и не подконтрольные прямому руководителю, однако также существует процессы, которые необходимо тщательное внимание со стороны руководства).

В Российской Федерации сложилась общая установленная система управления: «сверху-вниз» и «снизу-вверх». Такая система основана на постоянной переработки планов, сборе аналитической информации, обработки её и корректировки планов - как итога.Такая структура не решает все проблемы, но на данный момент она является общепринятой и наиболее эффективной для современной России [6].

Когда мы говорим о такой комплексной теме, необходимо отметить, что информационная база - это основа системы менеджмента. В информационную базу обычно включают такие понятия как внешняя и внутренняя среда. Если это внутренняя среда, то информация в ней может быть полностью подконтрольна руководству; если внешняя среда, то это элемент непредсказуемости для менеджмента компании. Когда мы говорим об информации о предприятии в целом, то основным источником будет являться годовая отчетность, налоговый и управленческий учёт, любые другие виды отчетности.

Учетная политика организации, положение по ведению бухгалтерского учета, график документооборота, график-планы, планы структурных подразделений - именно в таких документах отражаются потребности 
субъектов предприятия в информации, необходимой для планирования. Данные документы позволяют удовлетворить потребность менеджеров предприятия в учетной информации.

На каждом из предприятий существует собственная система документооборота, которая эффективна под конкретное из предприятий, однако также стоит отметить, что для каждого предприятия существует собственная специфическая система финансового планирования. Это происходит по причине уникальности каждой экономической деятельности и различных условиях внешней среды. Такой метод планирования характеризуется системой показателей, определенной методикой, процессами и т.д.

Финансовый план предприятия — это документ, отражающий объем поступлений и расходования денежных средств. Основная цель финансового планирования - предвидение будущих расходов предприятия с возможностью получения доходов, которые будут покрывать расходы и удовлетворять нуждам предприятия.

Как и любой документ на предприятии, финансовый план имеет собственные задачи: в нём отражаются обеспечение необходимыми финансовыми ресурсами подразделений; ответственность за эффективность инвестиций; этапы хозяйственной деятельности; определяются методы вложения капитала; оценивается рациональное использования ресурсов; рассматриваются внутрихозяйственные резервы; пути максимизации использования имеющихся ресурсов - целях экономии денежных средств - устанавливается рациональное отношение с бюджетом, банками, покупателями, поставщиками, подрядчиками; в нём также рассматривается отношение к акционерам и другим инвесторам; платежеспособность и кредитоспособность предприятия - все это описывается в данном документе.

Финансовое планирование выполняет большое количество функций, опирающихся на финансовые отношения: между предприятиями и 
различными хозяйствующими субъектами по поводу реализации товаров или услуг; порядка кредитования - отношения между акционерами и собственниками предприятия; трудовыми коллективами работников и отдельными лицами - по поводу оплаты рабочего времени, отдельными подразделениями, участвующими во внутреннем финансировании, другими предприятиями, государственным бюджетом, банками и страховыми организациями[1].

Финансовый план помогает контролировать данные взаимоотношения, что позволяет заранее предвидеть финансовые потери или получение денежных средств, оптимизировать денежные потоки. Финансовый план обычно составляется в виде баланса доходов и расходов, и отдельных статей, по которым можно будет детально в дальнейшем проводить анализ. Детализация данных статей может быть разной: от упрощенного варианта до структурированного. Так как данный документ может быть составлен в свободной форме - он довольно гибок по своей структуре. Для повышения достоверности некоторые статьи данного финансового плана, представляемые для инвесторов и владельцев, могут быть детализированы [7].

Финансовое планирование - это процесс постепенного усовершенствования менеджмента. Финансовое планирование всегда развивается, учитывая условия экономической системы. По этой причине такими направлениями улучшения можно считать:

- сокращение расходов;

- увеличение продаж;

— увеличение нормы прибыли;

— улучшение структуризации;

— оптимизации;

- усиления детализации процессов и отражения их в учетных документах.

Сформированные на этапе создания финансового плана, показатели 
могут не совпадать с фактическими по итогу периода. Это происходит из-за неправильного прогнозирования со стороны руководства, однако, это может также происходить в случаях изменяющейся конъюктуры рынка.

Анализ производится следующим образом: организаторы финансового планирования сравнивают плановые значения, то есть идеальные показатели с фактическими, и производят анализ эффективности.[4].

Необходимо также отметить, что финансовый план не может быть всегда досконально проработанным (на практике это чаще всего происходит), поэтому процедура улучшения плана- это процесс не такой формальный, а скорее творческий.Это не означает, что сам план должен быть нечетким -это значит, что подход к его составлению должен быть уникальным - - актуальным для каждого предприятия [3].

Процедура формирования улучшенного плана может иметь различные этапы. В общем мере улучшение такого плана можно охарактеризовать как:

— поиск несоответствий;

- поиск влияющих факторов;

— настройка параметров, требующих изменения;

- установка предельных значения таких параметров;

- определение этапов достижения приемлемых уровней плана (без принятия каких-либо ограничивающих факторов).

Корректировка целей (если в связи с изменением плана понятно, что первоначальная цель не релевантна к нынешним условиям) имеет свое место в структуре улучшения финансового плана [2].

Выявлять несоответствия плановых, идеальных показателей, всегда следует в двух формах: в абсолютном и относительном. Абсолютная форма это изменение одного значение к другому. Относительная форма - это процентное изменение показателей. Если в плане компании были заложены слишком нереалистичные ожидания и требования, и по итогу, например, года видно, что компания не добилась успехов, значит, показатели следует пересмотреть. Такими целевыми показателями могут являться объем продаж 
или прибыль. Однако для высшего менеджмента гораздо более привычны показатели рентабельность и прибыль на капитал.

Вышеназванные основы менеджмента чаще всего применяются на предприятиях в России. Однако сейчас происходит ужесточение конкуренции, что влечёт за собой потребность в усовершенствовании процесса финансового планирования. Решением данной проблемы чаще всего является изучение методик в финансовом менеджменте зарубежных предприятий, сходных по деятельности. Такие методики адаптируются и успешно применяются. Существующая система учёта довольна эффективна. Однако она требует усовершенствования методов планирования и управления. Также оказывает помощь в решении поставленных задач улучшение информационных технологий, которые нацелены на корректировку процесса принятия управленческих решений.

В менеджменте считается, что поставленные цели компании должны быть подчиненны главной миссии компании. Цели же должны быть актуализированы под конкретные рыночные условия, полученные из анализа внешней и внутренней среды.

Процесс постановки целей принято делить на 2 этапа: определение качественных показателей (вектор развития предприятия) и определение количественных параметров этих целей.

В условиях рыночной экономики бюджет, как один из инструментов финансового планирования, становится незаменимым инструментом. Бюджет - форма финансового плана. Большая неопределенность обусловливает необходимость введения оперативных бюджетов таких как: квартальных, месячных и др.

Для развивающихся рынков долгосрочное планирование очень большая проблема. По этой причине качественная финансовая политика на 10-15 лет трудная задача. Однако, существует и другая проблема: такое краткосрочное планирование не позволяет с высокой вероятностью прогнозировать рентабельность выбранного бизнеса, поэтому наиболее 
альтернативный вид прогнозирования для таких рыночных условий является прогнозирование на 3-5месяцев в случае краткосрочного, и 1- 5 лет в случае долгосрочного.

Долгосрочный финансовый план показывает перспективы деятельности компании. Бюджет, как инструмент, позволяет увидеть фактические параметры, которые позволят скорректировать дальнейший вектор развития компании. Долгосрочный план корректируется в редких случаях. Он менее детализирован, в нём учитываются только главные финансовые цели.

K новым направлениям в системе финансового планирования относится«скользящий план». Он позволяет: по итогам одного квартала вводить небольшие корректировки в долгосрочный план --по итогу компания получает долгосрочный бюджет с четко определенными целями, но при этом гибкую структуру, которая может быть адаптивна к изменяющимся условиям.

Для повышения эффективности такой системы планирования управляющий менеджмент должен поставить перед собой 2 цели: первое перед коммерческой службой - повышение выручки за счёт оптимизации всех процессов; второе - перед финансовой службой - понижение затрат [2].

Благоприятная среда позволяет улучшать качество финансового планирования. Такая среда характеризуется внутренней системой управления: коммуникацией подразделений, эффективной структурой бюджетирования и системы внутреннего контроля и менеджмента. Эффективность может достигаться за счет расширения полномочий и увеличения обязанностей, проверкой учетных документов и четкого документооборота.

Управляющие, которые отвечают за контрольные функции, являются важнейшим элементом системы внутреннего контроля и финансового планирования. Такой управляющий персонал, как бухгалтеры, не должны часто сменяться, так как отсутствие опыта работы в конкретной компании 
приводит к слабому финансовому менеджменту. Если новый руководитель и управляющий персонал не знаком с внутренней системой управления в организации, то тогда существует вероятность неполучения прибыли в долгосрочной перспективе[4].

Подводя промежуточный итог, смена любого управляющего персонала довольно критична для процесса финансового планирования, так как финансовое планирование имеет элемент творчества, то изменения данного аспекта- в лице управляющего персонала - может сильно повлиять на вектор управления и вектор развития компании. Говоря о персонале, необходимо также сказать, что в компании должно существовать чёткое иерархическое разделение обязанностей. Такое разделение поможет выявить слабые аспекты компании и улучшить их в максимально сжатые сроки.

Необходимо также проводить стратегический контроль, так как всегда могут быть допущены ошибки при начальном этапе планирования. Однако, неправильно выбранное направление развития компании может влиять на жизнеспособность и эффективность действия компании.Для нивелирования угроз необходимо выполнить три этапа:

- контроль предпосылок;

— контроль реализации;

- стратегические надзор.

Система внутреннего контроля может быть подразделена на три составляющих: контрольная среда (набор характеристик, который определяет взаимоотношения между подразделениями), система управленческого учёта предприятия (учетная политика и процессы документооборота), процедура контроля (специальные проверки, выполняемые управляющими на предприятии) [5].

Такие три составляющие взаимосвязаны, они обеспечивают нивелирования угроз и рисков, что позволяет избежать искажения информации, и в дальнейшем на её основе прогнозируются действия предприятия. Процесс контроля - это выработка стандартов и критериев 
сравнения реальных показателей с идеальными.

Финансовое планирование - это всегда процесс предотвращения деградации, задействования потенциала успеха и выявление предпосылок к новому развитию. Любые предпосылки, обусловленные потребностями рынка, изменения конкурентов, государственных структур - должны быть использованы при финансовом планировании управляющими.

Подводя итог необходимо отметить, что финансовое планирование это часть внутреннего планирования. На данный момент ни одна из организаций в Российской Федерации не может осуществлять свою деятельность без финансового планирования. Разница лишь в том, что крупные предприятия оптимизируют этот процесс эффективнее. Финансовое планирование - это бесконечный процесс собственного самосовершенствования, детализации и контроллинга. Финансовое планирование - это ключ к избеганию рисков и увеличения прибыльности в долгосрочной перспективе.

\section{СПИСОК ЛИТЕРАТУРЫ:}

1. Ананьев А.В., Каратеев О.В. К вопросу актуальности бизнеспланирования// Символ науки. № 10. 2018. - С. 14- 16.

2. Беляева О.В., Мягкова Т.Л. Необходимость совершенствования бизнеспланирования на предприятии // Наука и инновации в системе развития информационного общества. 2019. С. 105-109.

3. Боровик Д.А., Сбойлова Л.Е. Разработка и реализация бизнеспланов в условиях пандемии вируса COVID-19 // Вестник молодежной науки. 2020. № 3 (25). С. 1.

4. Макаркин Н.П., Мазова Е.В. Бизнес-планирование на предприятии // Энергоэффективные и ресурсосберегающие технологии и системы. 2018. C. 566-570.

5. Пирнаева А.Ю., Омарова 3.М. Значение бизнес-планирования в 
деятельности фирмы в современных условиях // Вестник Академии знаний. 2019. № 6 (35). С. 237-242.

6. Шумилина, В. Е. Роль риск-менеджмента в обеспечении экономической безопасности предприятия / В. Е. Шумилина, Т. А. Адамов // Управление предприятиями и организациями: проблемы и решения : AUS PUBLISHERS, 2021. - С. 73-84.

7. Шумилин, П. Е. Бухгалтерская модель системы поддержки принятия решений / П. Е. Шумилин, В. А. Еременко // Научное обозрение: теория и практика. - 2020. - Т. 10. - № 4(72). - С. 612-619. - DOI 10.35679/2226-0226-2020-10-4-612-619.

8. Шумилина, В. Е. Пути повышения финансовой устойчивости предприятия для обеспечения экономической безопасности / В. Е. Шумилина, К. Н. Абдуллаева, Т. В. Сушкова // : Современные проблемы экономической безопасности, учета и права в Российской Федерации. Том 4, 11 января 2018 года - 312019 года, 2019. - С. 5. DOI 10.26526/conferencearticle_5c50616cd8cac1.84580638.

9. Шумилина, В. Е. Финансовые механизмы управления прибылью предприятия / В. Е. Шумилина, В. В. Саркисьян, А. В. Близнюкова // Актуальные вопросы обеспечения экономической безопасности в Российской Федерации в условиях цифровой экономики. - Мельбурн : AUS PUBLISHERS, 2018. - C. 1-7.

\section{References}

1. Ananiev A.V., Karateev O.V. To the question of the relevance of business planning // Symbol of Science. No. 10. 2018. - P. 14-16.

2. Belyaeva O.V., Myagkova T.L. The need to improve business planning at the enterprise // Science and innovations in the development system of the information society. 2019.S. 105-109.

3. Borovik D.A., Sboilova L.E. Development and implementation of business plans in the context of the COVID-19 virus pandemic // Bulletin of Youth 
Science. 2020. No. 3 (25). P. 1.

4. Makarkin N.P., Mazova E.V. Business planning at the enterprise // Energyefficient and resource-saving technologies and systems. 2018.S. 566-570.

5. Pirnaeva A.Yu., Omarova Z.M. The value of business planning in the activities of the company in modern conditions // Bulletin of the Academy of Knowledge. 2019. No. 6 (35). S. 237-242.

6. Shumilina, V. E. The role of risk management in ensuring the economic security of an enterprise / V. E. Shumilina, T. A. Adamov // Management of enterprises and organizations: problems and solutions: AUS PUBLISHERS, 2021. - P. 73- 84.

7. Shumilin, P. E. Accounting model of the decision support system / P. E. Shumilin, V. A. Eremenko // Scientific review: theory and practice. - 2020. T. 10. - No. 4 (72). - S. 612-619. - DOI 10.35679 / 2226-0226-2020-10-4612-619.

8. Shumilina, V. E. Ways of increasing the financial stability of an enterprise to ensure economic security / V. E. Shumilina, K. N. Abdullayeva, T. V. Sushkova //: Modern problems of economic security, accounting and law in the Russian Federation. Volume 4, January 11, 2018 - 31 2019, 2019 .-- P. 5. - DOI 10.26526 / conferencearticle_5c50616cd8cac1.84580638.

9. Shumilina, V. E. Financial mechanisms of enterprise profit management / V. E. Shumilina, V. V. Sarkisyan, A. V. Bliznyukova // Topical issues of ensuring economic security in the Russian Federation in the digital economy. - Melbourne: AUS PUBLISHERS, 2018 .-- S. 1-7. 